\title{
A Grid Connected Three-Port Solar Micro Inverter
}

\author{
V. Rinsha, Jinu Mathew Varghese and Dr. M. Shahin
}

\begin{abstract}
In the present scenario of increasing energy crisis Interest in ac module strategy for $P V$ based microinverter has grown in recent years because of its improved energy harvest, improved system efficiency, lower installation costs, plug-N-play operation, and enhanced flexibility and modularity .Microinverters avoid the drastic reduction in power produced by $P V$ panels due to shading effect. In this paper a three-port microinverter topology is being studied which is connected to single phase grid. The proposed topology is basically a flyback converter with an extra switch and diode. This arrangement allows the use of a low capacitance film capacitor, with long lifespan, as decoupling capacitor instead of E-caps, with short lifespan. Thus proposed three-port microinverter has longer lifespan.The operation principles and design considerations are explained in this paper. The MATLAB/SIMULINK based simulation of the microinverter is also performed.
\end{abstract}

Keywords--- AC Modules, Flyback Converter, Maximum Power Point Tracking (MPPT), Power Decoupling, ThreePort Micro Inverter, Utility Interactive Inverter

\section{INTRODUCTION}

$\mathrm{T}$ HE renewable energy sources, such as wind turbine, photovoltaic (PV) panels, etc. become more and more popular in industrial and residential applications, because of the energy crisis. Due to their promise of clear and seemingly limitless generated energy the photovoltaic (PV) has witnessed the unprecedented growth, among renewable sources [1]-[3]. With different radiance and temperature, the dc output voltage and the maximum output power of the PV panel will change. So, an inverter interface with maximum power point tracking (MPPT) is required for the PV panel to connect to the grid. There are three popular technologies for the PV panels connected to the grid through an inverter: centralized threephase inverter for matrix connected PV panels, single-phase string inverter for series connected PV panels and module

V. Rinsha, M.Tech, Student, Electrical and Electronics Department, Government College of Engineering, Kannur, India. E-mail: rinshaibrahim12@gmail.com

Jinu Mathew Varghese, M.Tech, Student, Electrical and Electronics Department, Government College of Engineering, Kannur, India. E-mail: jinumathew72@gmail.com

Dr.M. Shahin, Associate Professor, Electrical and Electronics Department, Government College of Engineering, Kannur, India. E-mail: shahinmtly@gmail.com integrated micro-inverter for a single PV panel [4]-[7].The centralized inverter structure is shown in Fig. 1(a). ${ }^{1}$

Due to low cost and high reliability, module integrated micro-inverter which is shown in Fig. 1(b), is preferred for the future application. It removes the mismatch losses between PV modules since there is only one PV module, and also supports optimal adjustment between the PV module and the inverter and, hence, the individual MPPT.
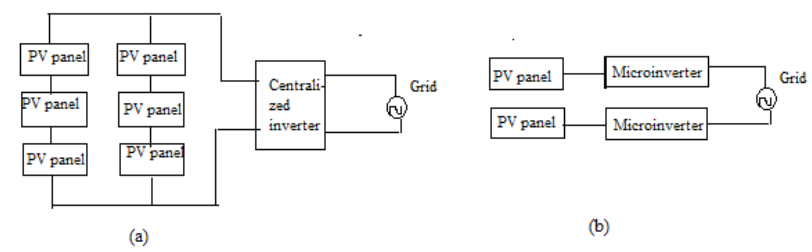

Fig. 1: (a) Centralized Inverter (b) Micro Inverter Structure

It includes the possibility of easy enlarging of the system, due to the modular structure. The microinverter can be used as a "plug and play" device, which can be used by persons without any knowledge of electrical installations, is also an inherent feature of microinverter based ac module.

Based on the galvanic isolation, the PV inverter topologies can be divided into transformer-less topologies and transformer isolated topologies. Since the output voltage of a single PV panel is as low as $20 \sim 50 \mathrm{~V}$, a high voltage gain inverter is required for the PV panel to connect to the singlephase grid. Although the transformer-less inverter topologies have low cost and high efficiency features, they usually do not have enough voltage gain to boost the input voltage. Therefore, the transformer isolated inverter topologies with high voltage gain are preferred for a single PV panel gridconnected application.

For the transformer isolated inverter topologies, there are two popular approaches. The first approach utilizes the single stage flyback inverter or isolated buck-boost inverter, which is able to replace the electrolytic capacitor with high voltage low capacitance film capacitor for the energy storage. This approach usually uses less switches with low cost, the high frequency transformer is the major design issue for these topologies to achieve high efficiency. The second approach is two-stage approach with a transformer isolated dc-dc converter as the first stage and a full-bridge inverter as the second stage [8]. A high efficiency dc-dc converter with soft switching is usually designed for the first stage. A full bridge inverter with line frequency switches or PWM is usually used for the second stage. The dc-dc converter in the first stage is

\section{DOI : 10.9756/BIJPSIC.4873}


the major design issue to achieve low cost and high efficiency. Fig. 2 shows the block diagram of conventional two stage isolated solar microinverter.

The dc-dc converter in first stage releases the maximum solar energy from a PV panel and provides a high voltage dc bus for the second stage dc-ac inverter that converts the dc voltage to a sinusoidal ac output voltage and connects with the ac grid system. The conversion efficiency of the conventional solar microinverter is poor due to the two-stage power conversion. High-voltage electrolytic capacitors (E-Caps) are usually necessary on the dc bus between the dc-dc and dc-ac stages. They are expensive and seriously shorten the lifespan of the solar microinverter that is cyclically exposed to a high temperature environment under solar irradiation. The commercial success of the module-integrated microinverter depends on its reliability and efficiency and long lifespan and low power loss must be ensured.

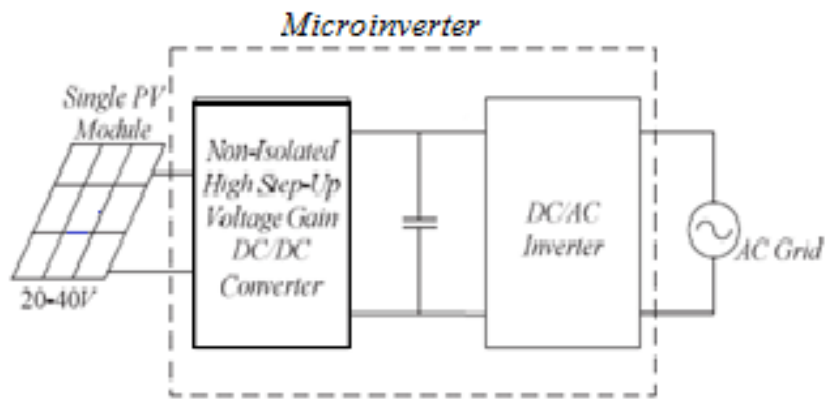

Fig. 2: Block Diagram of Conventional Solar Micro Inverter

A three-port converter is a best choice for power decoupling in a single stage inverter [9]-[13].Here one port is dedicated for MPPT task and other is dedicated for power decoupling. In this paper, a three-port microinverter based on flyback topology which can perform both dc- ac conversion and power decoupling has been proposed [14]. Simple topology, less power loss and decent efficiency are the advantages of the proposed topology. In this topology conventional snubber circuit is also not required as the decoupling capacitor act as snubber circuit. The operation principles and design considerations will be analyzed and described in the following sections. This paper is organized as follows. The system description and operation states analysis is given in section II. The design considerations are given in section III. The results and discussion are given in section IV and section $\mathrm{V}$ respectively, followed by conclusion in section VI.

\section{SYSTEM DESCRIPTION AND OPERATION}

The proposed topology as shown in Fig. 3 is a basic flyback topology with an extra switch $\mathrm{S}_{2}$ and a diode $\mathrm{D}_{2}$. A high frequency flyback transformer is used here. The secondary of transformer have two windings to produce the ac output voltage using the two switches $S_{3}$ and $S_{4}$ in series with diodes $\mathrm{D}_{3}$ and $\mathrm{D}_{4}$ which are switching at line frequency. The power decoupling is performed by decoupling capacitance $C_{D}$. When the Input power is higher than the output power $\left(\mathrm{P}_{\mathrm{in}}>\mathrm{P}_{\mathrm{o}}\right)$ surplus power is stored in the decoupling capacitor and in the other case when input power is less than output power $\left(\mathrm{P}_{\mathrm{o}}>\right.$ $\mathrm{P}_{\text {in }}$ ) then the deficit power is being supplied from the decoupling capacitor by turning on switch $\mathrm{S}_{2}$. Hence the operating mode of this topology is divided into two modes as shown in Fig. 4.

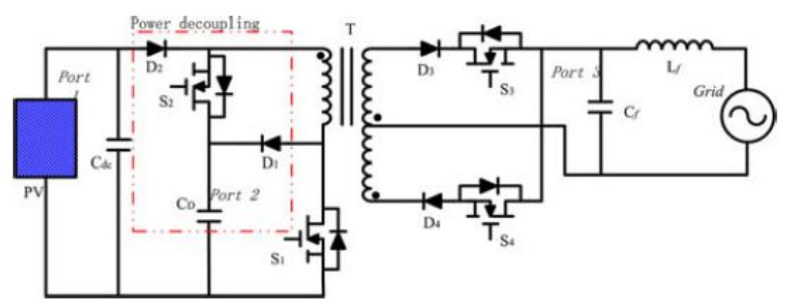

Fig. 3: Proposed Three-Port Micro Inverter [14]

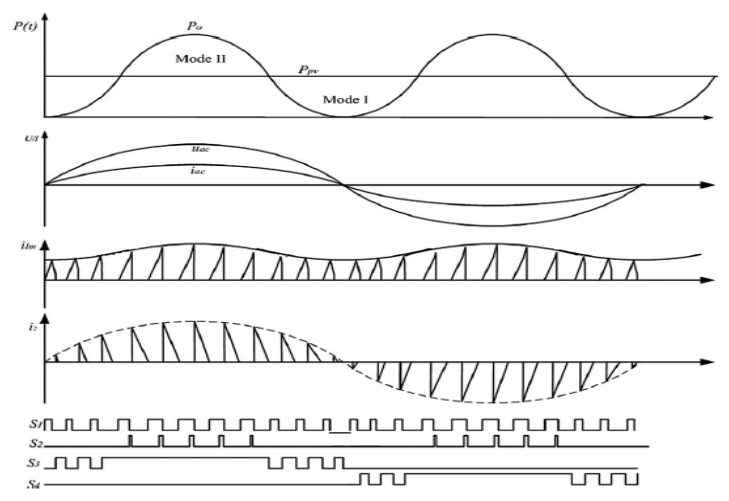

Fig. 4: Waveforms

When the input power from $\mathrm{PV}, \mathrm{P}_{\mathrm{PV}}$ is larger than output power $\mathrm{P}_{\mathrm{o}}$, the inverter operates in mode $\mathrm{I}$ and when $\mathrm{P}_{\mathrm{o}}>\mathrm{P}_{\mathrm{PV}}$ inverter operates in Mode II.

\section{A. Mode I}

In this mode the extra energy from the PV panel will be stored in the decoupling capacitor $C_{D}$ and switches $S_{1}, S_{3}\left(S_{4}\right)$ are operating while $S_{2}$ and $S_{4}\left(S_{3}\right)$ are always OFF. The operation in this mode is divided into four circuit states in each switching cycle, as shown in Fig.5.

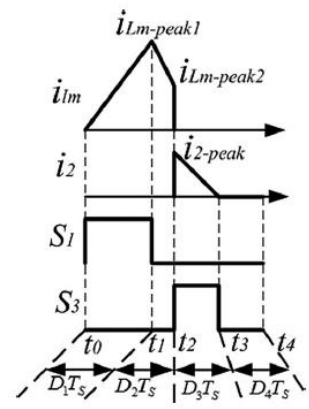

Fig. 5: Switching Waveforms for $S_{1}$ and $S_{3}$

Each state, as shown in Fig. 6, will be discussed in detail.

State $1\left[t_{0}-t_{1}\right]$ : During this state, shown in Fig. 6(a), S1 is turned $\mathrm{ON}$, and the magnetizing inductance starts storing energy from the PV panel. The magnetizing current keeps 
ramping up and once it reaches its peak value $\left(i_{L m \text { peak } 1}\right), \mathrm{S} 1$ is turned OFF, and the next stage starts.

$$
i_{\text {Lm_peak1 }}=\frac{V_{\text {in }}}{L_{m}} D_{1} T_{S}
$$

State $2\left[t_{1}-t_{2}\right]$ : All switches are OFF during this mode ,as in Fig. 5(b). The transformer magnetizing energy will discharge into the decoupling capacitor. The current will keep discharging until it reaches the current, $i_{L m \text { peak2 }}$, which is given as (2).

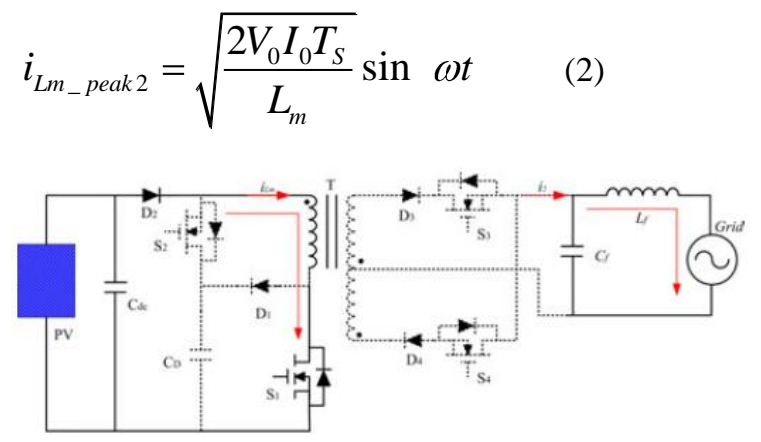

(a) State $1\left(t_{0}-t_{1}\right)$

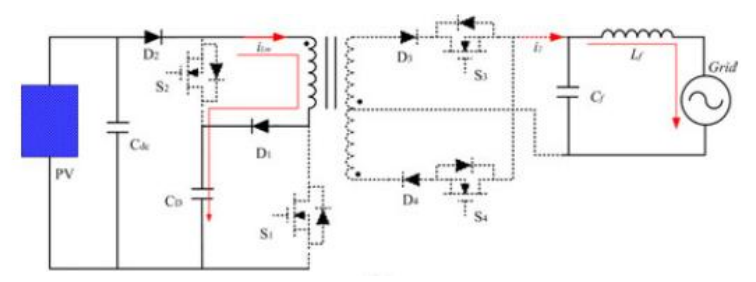

(b) State $2\left(\mathrm{t}_{1}-\mathrm{t}_{2}\right)$

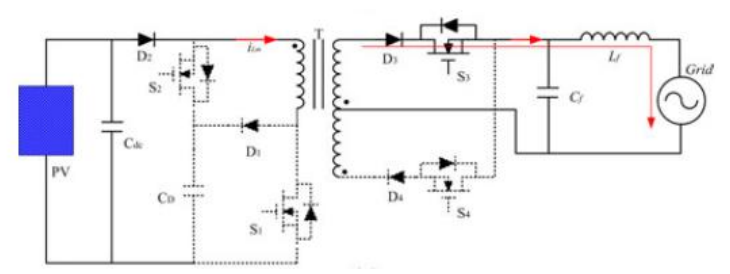

(c) State $3\left(t_{2}-t_{3}\right)$

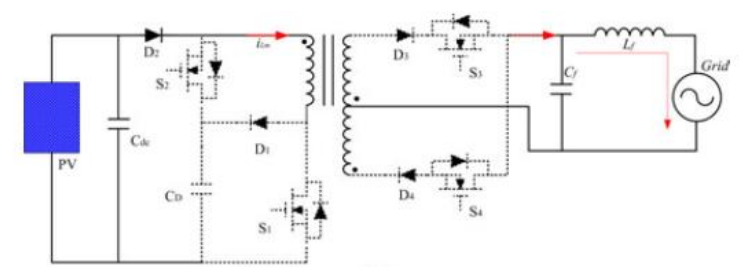

(d) State $4\left(\mathrm{t}_{3}-\mathrm{t}_{4}\right)$

Fig. 6: Operation States during Mode I [14]

The duty cycles D1 and D2 can be calculated by equation (3) and (4)

$$
\begin{gathered}
D_{1} T_{S}=\frac{L_{m} i_{L m_{-} \text {peak } 1}}{V_{\text {in }}} \\
D_{2} T_{S}=\frac{L_{m} i_{L m_{-} \text {peak } 2}-i_{\text {Lm_peak } 1}}{V_{\text {in }}-V_{\mathrm{C}_{\mathrm{D}}}}
\end{gathered}
$$

The total power from the PV panel from this two stages is given as (5)

$$
P_{i n}=\frac{1}{2}\left[i_{\text {Lm } p \text { peak } 1} D_{1} V_{\text {in }}+i_{L m_{-} \text {peak } 1}+i_{\text {Lm_peak } 2} D_{2} V_{\text {in }}\right]
$$

Substituting (3) and (4) in (5) $i_{\text {Lm_peakl }}$ is given as:

$$
i_{\text {Lm_peak } 1}=\sqrt{\left(\frac{V_{\text {in }}}{V_{\mathrm{C}_{\mathrm{D}}}} \times i_{L_{m_{-} \text {peak } 2}}\right)^{2}-\left(\frac{2 P_{\text {in }} T_{S}}{L_{m}}\right)\left(\frac{V_{\text {in }}}{V_{\mathrm{C}_{\mathrm{D}}}}-1\right)}(6)
$$

Equation (2) and (6) can be used to calculate $\mathrm{D}_{1}$ and $\mathrm{D}_{2}$.

State $3\left[t_{2}-t_{3}\right]$ : This state starts with turning on of switch $\mathrm{S}_{3}\left(\mathrm{~S}_{4}\right)$.As shown in Fig. 5(c), during this state, the current $i_{2}$ is released through one of the secondary windings, and the corresponding ac switch, either $\mathrm{S}_{3}$ or $\mathrm{S}_{4}$. The grid voltage during one switching period $v_{\mathrm{ac}}$ can be assumed to be constant; therefore, the current $i_{2}$ is expressed as

$$
i_{2}(t)=\frac{n_{1} i_{L m_{-} \text {peak } 2}}{n_{2}}-\left|\frac{v_{a c}}{L_{m 2}}\right| t-t_{3}
$$

The current $i_{2}$ reaches zero at $t_{3}$ and time duration $\mathrm{D}_{3} \mathrm{~T}_{\mathrm{S}}$ can be calculated by (8)

$$
D_{3} T_{S}=\frac{L_{m 2} \frac{2 n_{1} i_{\text {Lm_peak } 2}}{n_{2}}}{\left|v_{a c}\right|}
$$

State $4\left[t_{3}-t_{4}\right]$ : This state starts with current $i_{2}$ reaching zero. During this state, all the switches are turned OFF, as shown in Fig. 5(d). The capacitor $C_{r}$ and inductor $L_{r}$ keep pumping energy to the grid, and the flux in the flyback transformer is reset.

\section{B. Mode II}

This Mode is also divided into four states as shown in Fig.7. In Mode II, switch $\mathrm{S}_{3}\left(\mathrm{~S}_{4}\right)$ is always $\mathrm{ON}$. The first and third state of Fig. 8 is similar to Mode I. However the $i_{L m \text { peak } 1}$ is kept at the same level in this mode and hence according to equation (3) $D_{1} T_{S}$ remains constant in this mode. In the second state the decoupling capacitance discharges its energy through switch $\mathrm{S}_{2}$ and thus the time duration $\mathrm{D}_{2} \mathrm{~T}_{\mathrm{S}}$ can be calculated as:

$$
D_{2} T_{S}=\frac{L_{m} i_{\text {Lm_peak } 2}-i_{\text {Lm_peak } 1}}{V_{\mathrm{C}_{\mathrm{D}}}-V_{\mathrm{in}}}
$$

The calculation of $\mathrm{D}_{3} \mathrm{~T}_{\mathrm{S}}$ is same as Mode $\mathrm{I}$.

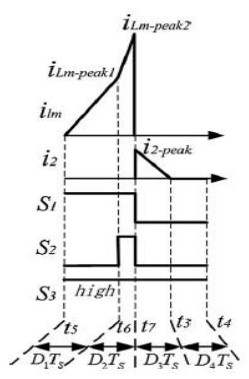

Fig. 7: Switching Waveforms for $S_{1}, S_{2}$ and $S_{3}$ 


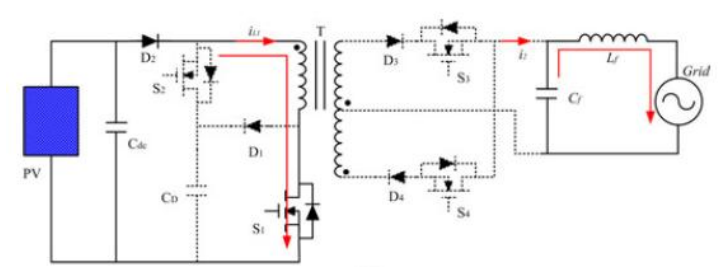

(a) State $1\left(t_{0}-t_{1}\right)$

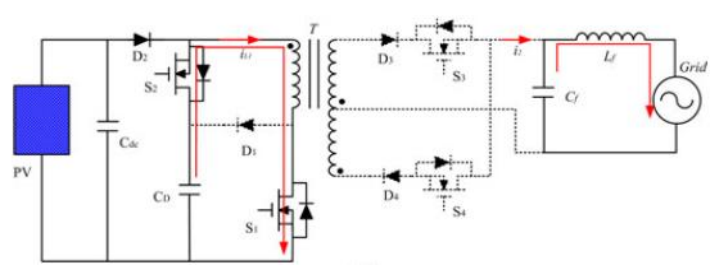

(b) State $2\left(\mathrm{t}_{1}-\mathrm{t}_{2}\right)$

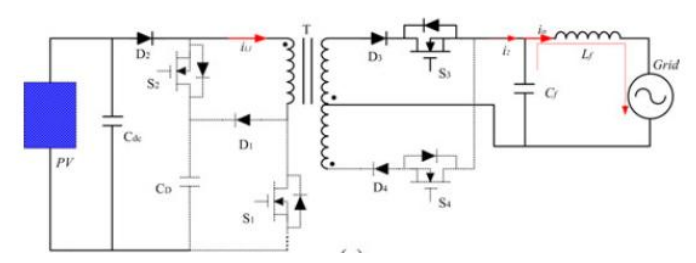

(c) State $3\left(t_{2}-t_{3}\right)$

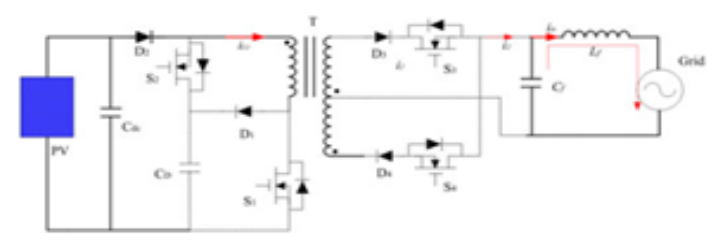

(d) State $4\left(\mathrm{t}_{3}-\mathrm{t}_{4}\right)$

Fig. 8: Operation States in Mode II [14]

\section{DESIGN CONSIDERATIONS}

Some design guidelines necessary for power device selection and decoupling capacitance value selection are given in this section.

\section{A. Power Device Voltage Stress}

The voltage across decoupling capacitance is pulsating at double-line frequency with a peak value of $V_{\text {peak }} c d$ whose value is determined by the selected capacitance and voltage ripple. Therefore, the voltage stress across $\mathrm{S}_{1}$ and $D_{1}$ is $V_{\text {peak_cd }}$ and the voltage stress on $\mathrm{S}_{2}$ and $D_{2}$ is $V_{\text {peak_cd }}-V_{\text {in }}$. When the output ac voltage is at its peak value, $v_{\text {ac_peak }}$ and when $S_{2}$ is turned $\mathrm{ON}, D_{3}$ or $D_{4}$ is subjected to peak voltages and the voltage stress is given as follows:

$$
V_{D 4_{-} \text {reverse }}=\frac{n_{2} V_{\text {peak-cd }}}{n_{1}}+v_{a c_{-} \text {peak }}
$$

Suppose in stage $3 S_{3}$ is ON and $S_{4}$ is OFF, the winding voltage corresponding to switch $S_{3}$ is clamped to grid voltage $v_{\mathrm{ac}}$. In this case, the symmetric secondary winding in transformer causes the winding voltage corresponding to $S_{4}$ to be $-v_{\text {ac }}$.Hence, the voltage stress on $\mathbf{S}_{4}$ is double grid voltage, and is given as:

$$
V_{S 4}=2 v_{a c_{-} p e a k}
$$

\section{B. Decoupling Capacitance}

The minimal voltage across the decoupling capacitor must be greater than the voltage stress across $S_{1}$, which given as follows:

$$
V_{S 1}=V_{i n}+\frac{n_{1}}{n_{2}} V_{0} \sin (2 \omega t)
$$

Otherwise, the energy stored in the primary side would damp into the decoupling capacitor.

\section{RESULTS}

A 200W PV panel supplying power to grid (230V) through proposed three-port microinverter was designed and simulated using MATLAB/SIMULINK. Specifications used for simulation is given in Table I.

First the PV panel was modelled and simulated [15] using MATLAB/SIMULINK and then proposed three-port microinverter model was connected to the PV panel that converted the dc voltage of PV to ac which is to be supplied to the grid.

Table I: Design Specifications

\begin{tabular}{|l|l|}
\hline \multicolumn{2}{|l|}{ PV Panel Specifications } \\
\hline Maximum Power $\left(\mathrm{P}_{\max }\right)$ & $200 \mathrm{~W}$ \\
\hline Voltage at Pmax $\left(\mathrm{V}_{\mathrm{mp}}\right)$ & $26.3 \mathrm{~V}$ \\
\hline Current at $\mathrm{P}_{\max }\left(\mathrm{I}_{\mathrm{mp}}\right)$ & $7.6 \mathrm{~A}$ \\
\hline Open-circuit voltage $\left(\mathrm{V}_{\mathrm{oc}}\right)$ & $31.7 \mathrm{~V}$ \\
\hline Short-circuit current $\left(\mathrm{I}_{\mathrm{sc}}\right)$ & $8.25 \mathrm{~A}$ \\
\hline Other Design Parameters \\
\hline Switching frequency & $50 \mathrm{kHz}$ \\
\hline Grid voltage & $230 \mathrm{~V}$ \\
\hline Grid frequency & $50 \mathrm{~Hz}$ \\
\hline
\end{tabular}

\section{A. PV Characteristics}

The MATLAB function code was written to obtain the module current under STC $\left(25^{\circ} \mathrm{C}, 1.5 \mathrm{AM}, 1000 \mathrm{~W} / \mathrm{m}^{2}\right)$. The IV curve and PV curve obtained from simulation of PV panel is shown in Fig.9 and Fig. 10 respectively.

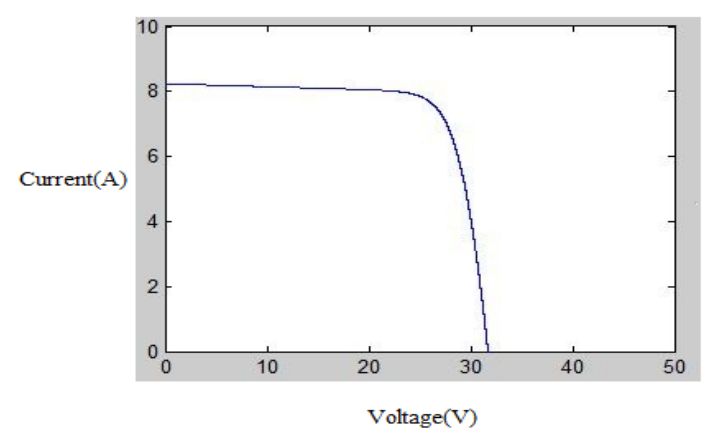

Fig. 9: I-V Characteristics of PV Panel 


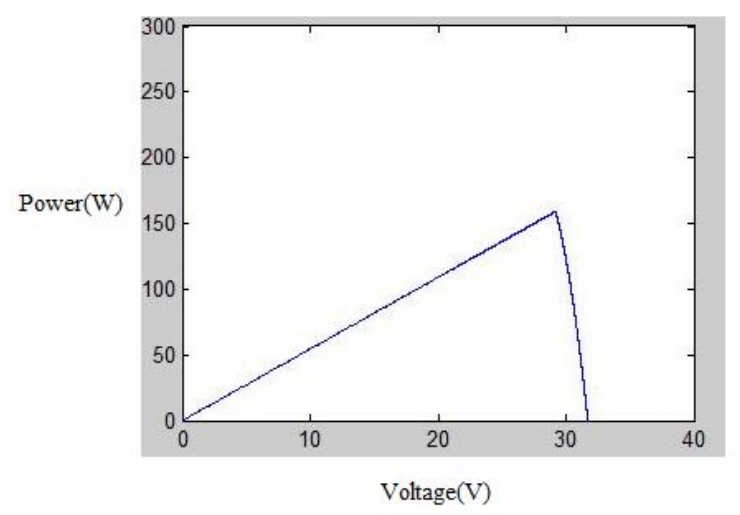

Fig. 10: P-V Characteristics of PV Panel

From Fig. 9 it is clear that the short circuit current and open circuit voltage obtained by simulation is same as given in Table I. The maximum power obtained by simulation is nearly $200 \mathrm{~W}$ as given in Table I.

\section{B. Circuit Simulation}

The simulation of the $100 \mathrm{~W}$ three-port microinverter was done using MATLAB/SIMULINK. The simulation model of three-port microinverter connected to $230 \mathrm{~V}$ grid is shown in Fig. 11

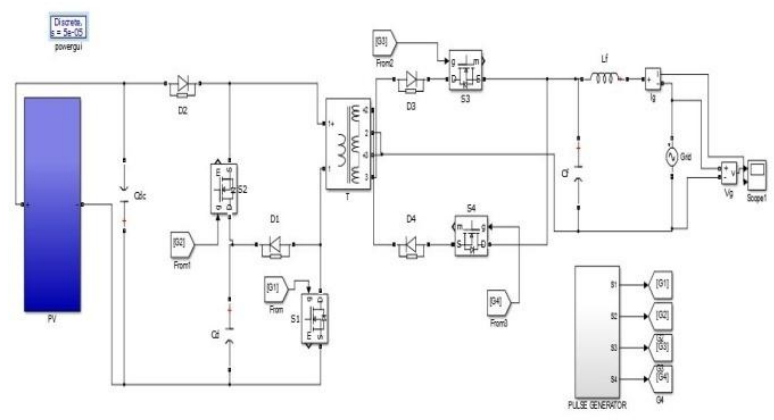

Fig. 11: Simulation Diagram of Three-Port Microinverter

The switching pulses for S1,S2,S3 and S4 where generated and are shown as Fig. 12.

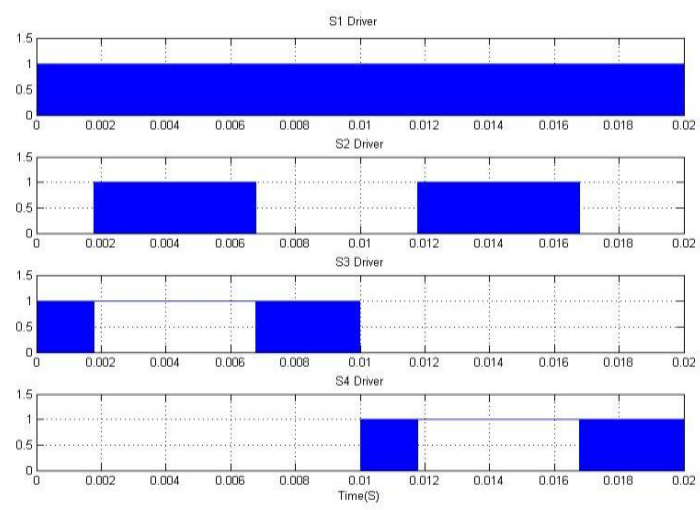

Fig. 12: Gate Pulses for Switches
The grid voltage and current waveform are shown in Fig. 13.The grid current is not purely sinusoidal as seen from Fig.13.
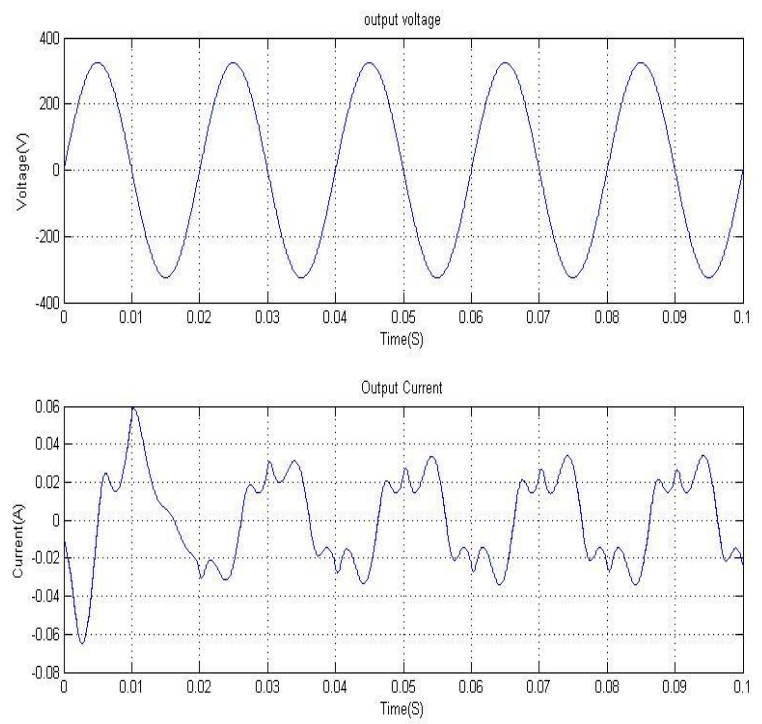

Fig. 13: Grid Voltage and Current

The three-port microinverter was simulated for different load conditions of $\mathrm{R}$ load other than connection to grid. The studied solar microinverter was found to be working under $\mathrm{R}$ load. The corresponding output waveforms are shown in Fig. 14.
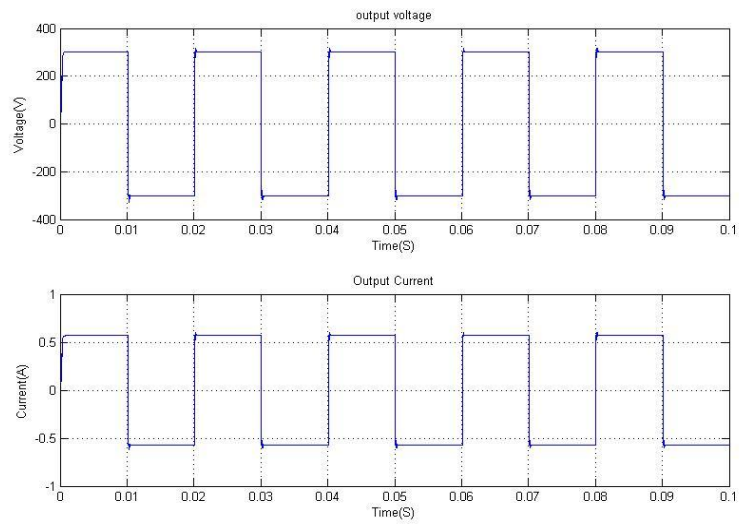

Fig. 14: Voltage and Current Output for R Load

From Fig. 14 it is clear that three-port solar microinverter works satisfactorily giving required output voltage irrespective of whether the load is R or grid.

\section{DISCUSSION}

Maximum power obtained from central inverter and string inverter based PV system reduce even when any one of the PV panel connected to them has been partially shaded .To avoid this problem a microinverter is used which is connected to a single PV panel. The main consideration while designing microinverter is its lifespan which is to be equal to the lifespan of PV panel. But the E-caps used in conventional microinverter have short lifespan. The three-port microinverter 
avoids this problem by using small capacitance for power decoupling and the same capacitance act as snubber circuit also. Also this microinverter is suited for $\mathrm{R}$ load and can be connected to grid.In case of grid connected three-port microinverter the output current was found to be non sinusoidal which can be mitigated by modifying the control methods.

\section{CONCLUSION}

A new microinverter topology has been presented in this paper. The lifetime of the three-port microinverter has been prolonged because of the replacement of high voltage E-caps with a new method of power decoupling with small film capacitance. The power decoupling capacitance also handles the transformer leakage energy and so avoids the need for extra dissipative circuits, which leads to reduced power losses and thus improved efficiency.

\section{REFERENCES}

[1] R. Mastromauro and M. Dell Liserre, "A control issues in single-stage photovoltaic systems: MPPT, current and voltage control," IEEE Transactions on Industrial Information, Volume 8, No. 2, pp. 241-254, May 2012

[2] Al Nabulsi and R. Dhaouadi, "Efficiency optimization of a DSP-based standalone PV system using fuzzy logic and dual-MPPT control," IEEE Transactions on Industrial Information, Volume 8, No. 3, pp. 573-584, August 2012

[3] T. Hirose and H. Matsuo, "Standalone hybrid wind-solar power generation system applying dump power control without dump load," IEEE Transactions on Industrial Electronics, Volume 59, No. 2, pp. 988-997, February 2012.

[4] S. B. Kjaer, J. H. Pedersen, and F. Blaabjerg, "A review of single-phase grid-connected inverters for photovoltaic modules," IEEE Transactions on Industrial Applications, volume 41, no. 5, pp. 1292-1306, September 2005

[5] Q. Li and P. Wolfs, "A review of the single phase photovoltaic module integrated converter topologies with three different dc link configurations," IEEE Transactions on Power Electronics, volume 23, no. 3, pp. 1320-1333, May 2008

[6] M. Calais, J. Myrzik, T. Spooner, and V. G. Agelidis, "Inverters for single-phase grid connected photovoltaic systems-An overview," in Proceedings in IEEE PESC'02, volume 2, 2002, pp. 1995-2000

[7] M. Meinhardt and G. Cramer, "Past, present and future of grid connected photovoltaic- and hybrid-power-systems," in Proceedings in IEEE-PES Summer Meeting, volume 2, 2000, pp. 1283-1288

[8] Cao, S. Jiang, and F. Z. Peng, Y. Li, "Low Cost Transformer Isolated Boost Half bridge Micro-inverter for Single-phase Grid-connected Photovoltaic System", in proceedings of Applied Power Electronics Conference and Exposition (APEC), Orlando, pp.71-78, February 2012.

[9] Z. Qian, O. Abdel-Rahman, H. Al-Atrash, and I. Batarseh, "Modeling and control of three-port $\mathrm{dc} / \mathrm{dc}$ converter interface for satellite applications,"IEEE Transactions on Power Electronics, volume 25, no. 3, pp. 637-649, March 2010

[10] Lohner, T. Meyer, and A. Nagel, "A new panel-integratable inverter concept for grid-connected photovoltaic systems," in Proceedings IEEE ISIE'96, volume 2, 1996, pp. 827-831

[11] Z. Qian, O. Abdel-Rahman, H. Hu, and I. Batarseh, "An integrated three-port inverter for stand-alone pv applications," in Proc. IEEE Energy Conversion Congress and Exposition, pp. 1471-1478, September $12-16,2010$

[12] H. Tao, A. Kotsopoulos, J. L. Duarte, and M. A. M. Hendrix, "Transformer-coupled multiport ZVS bidirectional dc-dc converter with wide input range," IEEE Transactions on Power Electronics, volume 23, no. 2, pp. 771-781, March 2008

[13] Z. Chuanhong, S. D. Round, and J. W. Kolar, "An isolated three-port bidirectional dc-dc converter with decoupled power flow management," IEEE Transactions on Power Electronics, volume 21, pp. 2443-2453, September 2008
[14] H. Hu, , S. Harb, N. H. Kutkut, Z. J. Shen, and I. Batarseh, ," A SingleStage Microinverter Without Using Eletrolytic Capacitors", IEEE Transactions on Power Electronics, volume 28, no. 6, June 2013

[15] S. Sheik Mohammed, "Modelling and Simulation of Photovoltaic module using MATLAB/Simulink," International Journal of Chemical and Environmental Engineering, Volume 2, No.5, October 2011 